\title{
Protocolo farmacoterápico para as clínicas de atenção básica do curso de
}

\section{Odontologia}

\author{
Pharmacotherapy protocol for primary care clinics of the Dentistry course \\ Protocolo de farmacoterapia para clínicas de atención primaria del curso de Odontología
}

Recebido: 04/02/2022 | Revisado: 10/02/2022 | Aceito: 13/02/2022 | Publicado: 20/02/2022

\author{
Filipe Farias Manta \\ ORCID: https://orcid.org/0000-0002-8776-0154 \\ Centro Universitário Maurício de Nassau, Brasil \\ E-mail: filipe-og@hotmail.com \\ Alan Pereira da Silva \\ ORCID: https://orcid.org/0000-0002-9842-7533 \\ Centro Universitário Maurício de Nassau, Brasil \\ E-mail: alan93ps@gmail.com \\ Gabriel Pereira Nunes \\ ORCID: https://orcid.org/0000-0001-7001-967X \\ Universidade Estadual Paulista, Brasil \\ E-mail: gabriel.pereira.nunes@hotmail.com \\ Ully Dias Nascimento Tavora Cavalcanti \\ ORCID: https://orcid.org/0000-0003-4748-1692 \\ Real Hospital Português de Beneficência, Brasil \\ E-mail: ullydias@gmail.com \\ Lucas Geazi da Silva Souza \\ ORCID: https://orcid.org/0000-0003-4932-3241 \\ Centro Universitário Braz Cubas, Brasil \\ E-mail: Geazilucas612@gmail.com \\ Eldson Lopes Antunes \\ ORCID: https://orcid.org/0000-0002-4048-560X \\ Faculdades Unidas do Norte de Minas, Brasil \\ Instituto Ciências da Saúde, Brasil \\ E-mail: Eldsonantunes@gmail.com
}

\begin{abstract}
Resumo
Introdução: A importância da prescrição medicamentosa na odontologia está bem estabelecida na literatura, apesar de existirem poucas publicações referentes a protocolos farmacológicos. A grande quantidade de medicamentos ofertados ao cirurgião-dentista (CD), com suas respectivas indicações, posologias, contraindicações e efeitos adversos, somam inseguranças na hora da escolha do medicamento mais adequado. Objetivo: Elaboração de um protocolo farmacoterápico, usando como meio de obtenção deste protocolo um código de resposta rápida (QR CODE), acessados através de dispositivos eletrônicos moveis. Método: avaliação da incidência de uso de medicamentos nas áreas de cirurgia oral menor, endodontia (e urgências endodônticas), periodontia, odontopediatria e como profilaxia antibiótica. Usando como critérios de inclusão artigos, livros e bulários da ANVISA entre os anos de 2006 a 2021. Resultados: Elaboração de um protocolo medicamentoso de uso adulto e infantil baseado em odontologia segundo a literaturas recentes, usando como meio de divulgação e acesso um QR CODE, acessível através de dispositivos eletrônicos moveis. Conclusão: A utilização de um método digital/eletrônico, onde grande parcela de profissionais e estudantes de odontologia tem acesso, colabora para ambos na tomada de decisões no momento da prescrição de uma droga, assegurando o conhecimento dos fármacos mais frequentes na odontologia.
\end{abstract}

Palavras-chave: Farmacologia; Prescrição; Protocolo.

\begin{abstract}
Introduction: The importance of prescription drugs in dentistry is well established in the literature, although there are few publications regarding pharmacological protocols. The large number of medications offered to the dental surgeon (CD), with their respective indications, dosages, contraindications and adverse effects, add insecurities when choosing the most appropriate medication. Objective: Elaboration of a pharmacotherapeutic protocol, using as a means to obtain this protocol a QR code, accessed through mobile electronic devices. Method: evaluation of the incidence of drug use in the areas of minor oral surgery, endodontics (and endodontic urgencies), periodontics, pediatric dentistry and as antibiotic prophylaxis. Using as inclusion criteria articles, books and bulletins of ANVISA between the years of 2006 to 2016. Results: Elaboration of a medical protocol for adult and child use based on dentistry according to recent literature, using as a means of disclosure and access a code of QR code, accessible through mobile electronic devices.
\end{abstract}


Conclusion: The use of a digital / electronic method, where large numbers of professionals and students of dentistry have access, collaborates for both in decision making at the moment of prescription of a drug, ensuring the knowledge of the most frequent drugs in dentistry.

Keywords: Parmacology; Prescription; Protocol.

\section{Resumen}

Introducción: La importancia de la prescripción de medicamentos en odontología está bien establecida en la literatura, aunque existen pocas publicaciones sobre protocolos farmacológicos. La gran cantidad de medicamentos que se ofrecen al odontólogo (DC), con sus respectivas indicaciones, posologías, contraindicaciones y efectos adversos, se suman a las inseguridades a la hora de elegir el fármaco más adecuado. Objetivo: Desarrollo de un protocolo farmacoterapéutico, utilizando un código de respuesta rápida (CÓDIGO QR) como medio de obtención de dicho protocolo, accediendo a través de dispositivos electrónicos móviles. Método: evaluación de la incidencia del uso de fármacos en las áreas de cirugía bucal menor, endodoncia (y urgencias endodónticas), periodoncia, odontopediatría y como profilaxis antibiótica. Utilizando artículos, libros y folletos de ANVISA como criterios de inclusión entre los años 2006 a 2016. Resultados: Elaboración de un protocolo de medicamentos para uso adulto e infantil basado en odontología según literatura reciente, utilizando como medio de difusión y acceso un CÓDIGO QR, accesible a través de dispositivos electrónicos móviles. Conclusión: El uso de un método digital/electrónico, al que tienen acceso un gran número de profesionales y estudiantes de odontología, colabora para ambos en la toma de decisiones a la hora de prescribir un fármaco, asegurando el conocimiento de los fármacos más frecuentes en odontología.

Palabras clave: Farmacología; Prescripción; Protocolo.

\section{Introdução}

A prescrição medicamentosa é uma diretriz, do cirurgião-dentista ou médico, destinada ao farmacêutico, com a finalidade de estabelecer a droga a ser utilizada, assim como, as instruções do uso da mesma (Araújo et al., 2012; Caliari et al., 2021). Segundo a lei $n^{\circ} 5.081 / 66$, compete ao cirurgião-dentista, a legalidade da prescrição de medicamentos de uso interno e externo, circunscritos na odontologia (Garbin, 2006). O ato de prescrever fármacos, é uma competência legal, implicando-se, assim um domínio verídico da farmacologia inerente a ação, posologia, reações adversas das drogas, envolvendo conteúdos de esfera legal, ética, técnica e clínica, estando seus autores suscetíveis as legislações de monitoramento e as ações da vigilância sanitária (Araújo et al., 2012). Além das características supracitados, o profissional da odontologia tem de levar em conta alguns aspectos, que não podem ser omitidos: indicações, contraindicações e efeitos colaterais (Garbin, 2006).

Se, de certa forma, uma boa anamnese leva ao correto diagnóstico de determinada lesão, do contrário, a mesma não terá relevância frente a prescrição se o profissional não tiver a lucidez necessária acerca da farmacologia (Carvalho et al., 2010; Neves et al., 2021). É essencial também, que haja comunicação entre o profissional e o paciente, com a finalidade do cirurgiãodentista assistir a evolução clínica pós tratamento, o que também propicia uma avaliação da prescrição e sua efetividade, ou ausência dela, além do aparecimento de reações adversas, que acarreta numa das melhores alternativas do cirurgiã-dentista dominar seu arsenal farmacológico (Garbin, 2006).

Visando assegurar ao paciente os efeitos benéficos da correta administração do fármaco e eliminando assim a automedicação, a prescrição deve ser embasada em normas vigentes do país. Em contra-argumento pode-se comprometer o entendimento, qualidade e eficiência do tratamento farmacológico, além de predispor a manifestação de eventos adversos (Souza, 2008).

Dentro da formação acadêmica, é essencial a presença de disciplinas básicas para uma construção integrada do conhecimento do cirurgião-dentista como clínico geral. Através dessas disciplinas, é possível subsidiar o conhecimento necessário para o desenvolvimento posterior de ciências especificas, tais quais, a farmacologia aplicada à odontologia. Aos incrementos periódicos de conhecimentos alicerçadores como citologia, bioquímica, fisiologia, farmacologia geral, entre outras, o acadêmico de odontologia adquire os pré-requisitos necessários para a compreensão das disciplinas voltadas para a prática odontológica propriamente dita. 
A correlação entre a farmacologia e a prescrição no manejo clínico, contribuem significativamente para o uso procedente dos medicamentos, proporcionando ao acadêmico maior garantia terapêutica, reduzindo assim, a margem de erro do mesmo (Souza et al., 2014; Souza, \& Pereira, 2021).

Objetivando a necessidade do domínio do acadêmico de odontologia frente aos fármacos que o mesmo pode administrar, este estudo visa elaborar um protocolo farmacoterápico, correlacionando os principais medicamentos utilizados em âmbito clínico na odontologia a suas indicações, contraindicações, posologias e reações adversas. Além da criação de material digital a ser utilizados em aparelhos eletrônicos (smartphones e tablets), utilizando o QR CODE como meio de acesso a este material.

\section{Metodoologia}

O estudo referido, classifica-se como artigo original, descritivo de natureza qualitativa (Nunes et al., 2021) e quantitativa e pesquisado de forma retrospectiva obtido nas bases de dados Bireme, Chocharne, SciELO, no livro: ANDRADE, Eduardo D. Terapêutica medicamentosa em odontologia. $3^{\text {a }}$ ed. São Paulo: Ed. Artes médicas 2014, no bulário eletrônico da Agência Nacional de Vigilância Sanitária (ANVISA) e na American Dental Associacion (ADA). Foram incluídas na pesquisa todos os trabalhos disponíveis nas bases anteriormente citadas publicados a partir de janeiro de 2006 a dezembro de 2021 de acesso livre, além de bulários de laboratórios registrados na ANVISA. Excluindo literaturas e bulários não disponíveis de livre acesso e escritos anteriormente a janeiro de 2006.

Explícitos na literatura, as intercorrências voltadas a odontologia onde se utilizavam medicamentos como meio interventivo, foram selecionadas e equiparadas a outros artigos com objetivo de verificar o fármaco utilizado, a posologia, indicação, contraindicações, faixas etárias e efeitos colaterais. Dentre a intercorrências ambulatoriais, podemos citar: cirurgias orais menor, urgências endodônticas, intervenção da dor, profilaxia antibiótica, intervenção em processos inflamatórios de origem dental, meios de combate a infecção generalizada de origem bucal, doenças que acometam o periodonto, além do combate a patologias provindas de agente etiológicos virais e fúngicos que acometem a cavidade oral.

Em seguida, foi realizado um levantamento das intercorrências acima citadas, juntamente com a conduta mais utilizada segundo a literatura, tomando como escolha decisiva o fármaco que apresentou maior evidencias científicas comprovadas quando utilizados para cada distúrbio de saúde oral e sistêmico descritos no parágrafo anterior. Contrapondo todos esses resultados descritos nos bancos de dados com bulários dos laboratórios regularmente inscritos na ANVISA.

\section{Resultados e Discussão}

Os Resultados do referido trabalho, foram descritos na formatação de um protocolo medicamentoso constando de antibióticos, anti-iflamátorios, antifúngicos, antivirais, anti-inflamatórios não esteroidais (AINEs), anti-inflamatórios esteroidais (AIEs) e analgésicos. Para cada grupo de medicamentos foram descritos a posologia adulta, posologia pediátrica, indicações envolvendo contexto odontológico, contraindicações e reações adversas. A seguir estão descritos por tópicos os resultados da pesquisa.

\subsection{Antibióticos}

Antibióticos são substâncias químicas naturais (sintetizados por fungos ou bactérias) ou sintéticos (penicilinas, cefalosporinas e as tetraciclinas), sendo as sintéticas a classe mais utilizada no meio odontológico (Pedroso, 2015). Os antibióticos têm indicação para tratar infecções odontogênicas, infecções orais não odontogênicas, profilaxia para o combate de infecções focais e infecções generalizadas de origem oral. 
Ainda podem ser classificados de acordo com a ação sob o agente etiológico da infecção, sendo eles bactericidas, quando ocorre a morte das bactérias causadoras, ou bacteriostáticas, quando ocorre a inibição do crescimento microbiano (Oliveira, 2011). Estão listados a seguir na tabela 1, os antibióticos mais prescritos em âmbito clínico.

Tabela 1: Antibióticos mais comumente utilizados em âmbito clínico.

\begin{tabular}{|c|c|c|c|c|c|}
\hline DROGA & $\begin{array}{l}\text { POSOLOGIA } \\
\text { ADULTA }\end{array}$ & $\begin{array}{l}\text { POSOLOGIA } \\
\text { PEDIÁTRICA }\end{array}$ & INDICAÇÕES & $\begin{array}{l}\text { CONTRA- } \\
\text { INDICAÇÕES }\end{array}$ & $\begin{array}{l}\text { EFEITOS } \\
\text { ADVERSOS }\end{array}$ \\
\hline $\begin{array}{l}\text { AMOXICILINA } \\
\text { 500MG } \\
\end{array}$ & 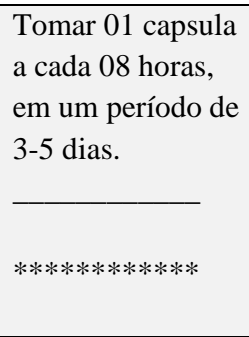 & $\begin{array}{l}* * * * * * * * * * * * \\
\\
\text { Tomar } 5 \mathrm{ml} 03 \\
\text { vezes ao dia, em } \\
\text { um intervalo de } 3- \\
5 \text { dias }\end{array}$ & $\begin{array}{l}\text { Tratamento de infecções } \\
\text { bacterianas por cepas } \\
\text { gram- positivas e } \\
\text { negativas, além do } \\
\text { tratamento de doenças } \\
\text { periodontais. }\end{array}$ & $\begin{array}{l}\text { Pacientes com } \\
\text { histórico de } \\
\text { hipersensibilidade a } \\
\text { antibióticos } \\
\text { betalactámicos }\end{array}$ & $\begin{array}{l}\text { Náuseas, } \\
\text { vômitos, tontura } \\
\text { e diarreia. }\end{array}$ \\
\hline $\begin{array}{l}\text { AMOXICILINA } \\
\text { 875MG }\end{array}$ & $\begin{array}{l}\text { Tomar } 01 \text { capsula } \\
\text { a cada } 12 \text { horas, } \\
\text { por um período } \\
\text { de } 3-5 \text { dias. }\end{array}$ & $* * * * * * * * * * * *$ & $\begin{array}{l}\text { Tratamento de infecções } \\
\text { bacterianas por cepas } \\
\text { gram- positivas e } \\
\text { negativas. }\end{array}$ & $\begin{array}{l}\text { Pacientes com } \\
\text { histórico de } \\
\text { hipersensibilidade a } \\
\text { antibióticos } \\
\text { betalactámicos }\end{array}$ & $\begin{array}{l}\text { Náuseas, } \\
\text { vômitos, tontura } \\
\text { e diarreia. }\end{array}$ \\
\hline $\begin{array}{l}\text { AMOXICILINA } \\
\text { 875MG }+ \\
\text { CLAVULANATO } \\
\text { DE POTÁSSIO } \\
\underline{\text { 125MG }}\end{array}$ & $\begin{array}{l}\text { Tomar } 01 \text { capsula } \\
\text { a cada } 12 \text { horas, } \\
\text { por um período } \\
\text { de } 3-5 \text { dias. }\end{array}$ & $* * * * * * * * * * * *$ & $\begin{array}{l}\text { Tratamento de curta } \\
\text { duração de infecções } \\
\text { bacterianas, quando se } \\
\text { suspeita que a causa } \\
\text { sejam cepas produtoras de } \\
\text { betalactamase resistentes } \\
\text { à amoxicilina }\end{array}$ & $\begin{array}{l}\text { Pacientes com } \\
\text { hipersensibilidade a } \\
\text { betalactâmicos; } \\
\text { pacientes com } \\
\text { histórico prévio de } \\
\text { icterícia/disfunção } \\
\text { hepática associadas } \\
\text { ao seu uso ou ao uso } \\
\text { de penicilina. }\end{array}$ & $\begin{array}{l}\text { Náuseas, } \\
\text { vômitos, } \\
\text { tontura, diarreia } \\
\text { e candidíase } \\
\text { mucocutânea. }\end{array}$ \\
\hline $\begin{array}{l}\text { CLINDAMICINA } \\
\text { SUSPENSÃO } \\
\underline{\text { 200MG }}\end{array}$ & $\begin{array}{l}\text { Tomar 01 capsula } \\
\text { a cada } 08 \text { horas, } \\
\text { por um período } \\
\text { de 3-5 dias. } \\
\\
\text { ************ }\end{array}$ & $\begin{array}{l}- \\
20-40 \mathrm{mg} / \mathrm{kg} / \mathrm{dia} \\
\text { de } 08 \mathrm{em} 08 \text { horas } \\
\text { entre } 7-10 \text { dias. }\end{array}$ & $\begin{array}{l}\text { Tratamento das infecções } \\
\text { causadas por bactérias } \\
\text { anaeróbicas susceptíveis, } \\
\text { por cepas susceptíveis de } \\
\text { bactérias aeróbias Gram- } \\
\text { positivas, além de } \\
\text { infecções dentárias, } \\
\text { incluindo abscessos } \\
\text { periodontais, periodontite, } \\
\text { gengivite e abscessos } \\
\text { periapicais; }\end{array}$ & $\begin{array}{l}\text { Pacientes que já } \\
\text { apresentaram } \\
\text { hipersensibilidade à } \\
\text { clindamicina ou à } \\
\text { lincomicina }\end{array}$ & $\begin{array}{l}\text { Eosinofilia, } \\
\text { diarreia e } \\
\text { Exame de } \\
\text { função hepática } \\
\text { anormal }\end{array}$ \\
\hline $\begin{array}{l}\text { CEFALEXINA } \\
\text { SUSPENSÃO } \\
\text { ORAL } \\
\text { 250MG/5ML }\end{array}$ & 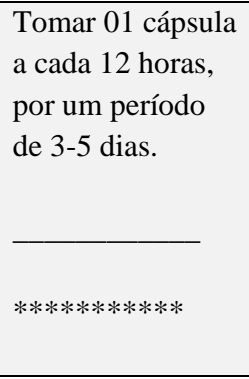 & $\begin{array}{l} \\
50-100 \mathrm{mg} / \mathrm{kg} / \mathrm{dia} \\
\text { durante por um } \\
\text { período de } 7-10 \\
\text { dias. }\end{array}$ & $\begin{array}{l}\text { Alternativa à amoxicilina } \\
\text { ou ampicilina na } \\
\text { prevenção de endocardite, } \\
\text { em pacientes alérgicos à } \\
\text { penicilina com alto risco } \\
\text { de endocardite bacteriana } \\
\text { após procedimentos } \\
\text { dentários }\end{array}$ & $\begin{array}{l}\text { Pacientes com } \\
\text { histórico de reação } \\
\text { alérgica a } \\
\text { penicilinas, } \\
\text { penicilamina ou } \\
\text { cefalosporinas. }\end{array}$ & $\begin{array}{l}\text { Raras reações } \\
\text { adversas de } \\
\text { dores } \\
\text { abdominais, } \\
\text { vômitos, } \\
\text { diarreia. } \\
\text { Nefrotóxicas em } \\
\text { altas doses. }\end{array}$ \\
\hline $\begin{array}{l}\text { AZITROMICINA } \\
\text { 200MG } \\
\text { SUSEPNSÃO } \\
\underline{\text { ORAL }}\end{array}$ & $\begin{array}{l}\text { Tomar } 01 \\
\text { comprimido por } \\
\text { dia, por um } \\
\text { período de } 3-5 \\
\text { dias. } \\
\end{array}$ & $\begin{array}{l} \\
\text { Tomar } 10- \\
20 \mathrm{mg} / \mathrm{kg} / \mathrm{dia}, \\
\text { durante } 3 \text { dias, }\end{array}$ & $\begin{array}{l}\text { Tratamento de infecções } \\
\text { bacterianas em cepas } \\
\text { susceptíveis. Tratamento } \\
\text { de abscesso periapical } \\
\text { agudo. }\end{array}$ & $\begin{array}{l}\text { Pacientes com } \\
\text { hipersensibilidade à } \\
\text { azitromicina, } \\
\text { eritromicina, a } \\
\text { qualquer antibiótico } \\
\text { macrolídeo e } \\
\text { cetolídeo }\end{array}$ & $\begin{array}{l}\text { Baixos relatos } \\
\text { de reações } \\
\text { indesejadas. }\end{array}$ \\
\hline
\end{tabular}




\begin{tabular}{l|l|l|l|l|l} 
& $\begin{array}{l}\text { não ultrapassando } \\
\text { 500mg diários }\end{array}$ & & $\begin{array}{l}\text { Tratamento de infecções } \\
\text { causadas por bactérias } \\
\text { anaeróbias; gengivite } \\
\text { ulcerativa necrosante, } \\
\text { periodontite crônica e } \\
\text { pericoronarites. }\end{array}$ & $\begin{array}{l}\text { Pacientes com } \\
\text { histórico de } \\
\text { hipersensibilidade } \\
\text { ao metronidazol ou } \\
\text { outro derivado } \\
\text { imidazólico }\end{array}$ & $\begin{array}{l}\text { Náusea, vômito, } \\
\text { diarreia, } \\
\text { alteração no } \\
\text { paladar } \\
\text { incluindo gosto } \\
\text { metálico e } \\
\text { mucosite oral. }\end{array}$ \\
\hline
\end{tabular}

Fonte: Autores.

\subsubsection{Profilaxia Antibiótica}

A endocardite infecciosa (EI) e profilaxia antibiótica (PA) é um assunto controverso e que vem passando por constantes mudanças. A EI é uma patologia infecciosa que afeta as superfícies endocárdicas produzindo inflamação e danos (Santos, 2015). A PA é recomendada nos casos de pacientes com condições cardíacas desfavoráveis ao desfecho da endocardite infecciosa, tais como: válvula cardíaca protética ou material protético utilizada para o reparo da válvula nos últimos 6 meses, história de endocardite infecciosa, transplante cardíaco que desenvolve valvulopatia cardíaca, cardiopatias congênitas, onde essas incluem cardiopatia congênita cianótica, cardiopatia congênita completamente reparada por material ou dispositivo protético nos últimos 6 meses e defeitos cardíacos congênitos com reparos locais ou adjacentes nos últimos 6 meses. Exceto para as situações anteriormente citadas, a PA não é recomendada para qualquer outra cardiopatia, já que os riscos de reações adversas aos fármacos, superam os benefícios trazidos pelo procedimento (ADA, 2016). Na Tabela 2, são listados esquemas farmacológicos para administração em casos de pro de PA.

Tabela 2: Antibióticos na prevenção da EI.

\begin{tabular}{|c|c|c|c|c|c|}
\hline DROGA & $\begin{array}{l}\text { POSOLOGIA } \\
\text { ADULTA }\end{array}$ & $\begin{array}{l}\text { POSOLOGIA } \\
\text { PEDIÁTRICA }\end{array}$ & INDICAÇÕES & $\begin{array}{c}\text { CONTRA- } \\
\text { INDICAÇÕES }\end{array}$ & $\begin{array}{c}\text { REAÇÕES } \\
\text { ADVERSAS }\end{array}$ \\
\hline $\begin{array}{l}\text { AMOXICILINA } \\
\text { VIA ORAL }\end{array}$ & $\begin{array}{l}2 \mathrm{~g}, 1 \text { horas antes do } \\
\text { procedimento }\end{array}$ & $\begin{array}{l}50 \mathrm{mg} / \mathrm{kg} 1 \text { hora } \\
\text { antes do } \\
\text { procedimento. }\end{array}$ & $\begin{array}{l}\text { Profilaxia } \\
\text { antibiótica }\end{array}$ & $\begin{array}{l}\text { Pacientes com histórico } \\
\text { de hipersensibilidade a } \\
\text { antibióticos } \\
\text { betalactámicos }\end{array}$ & $\begin{array}{l}\text { Náuseas, vômitos, } \\
\text { tontura e diarreia. }\end{array}$ \\
\hline $\begin{array}{l}\text { CLINDAMICINA } \\
\text { VIA ORAL }\end{array}$ & $\begin{array}{l}600 \mathrm{mg} 1 \text { hora antes } \\
\text { do procedimento. }\end{array}$ & $\begin{array}{l}20 \mathrm{mg} / \mathrm{kg} 1 \text { hora } \\
\text { antes do } \\
\text { procedimento. }\end{array}$ & $\begin{array}{l}\text { Profilaxia } \\
\text { antibiótica }\end{array}$ & $\begin{array}{c}\text { Pacientes que já } \\
\text { apresentaram } \\
\text { hipersensibilidade à } \\
\text { clindamicina ou à } \\
\text { lincomicina }\end{array}$ & $\begin{array}{l}\text { Eosinofilia, diarreia e } \\
\text { Exame de função } \\
\text { hepática anormal }\end{array}$ \\
\hline $\begin{array}{l}\text { AZITROMICINA } \\
\text { ORAL VIA }\end{array}$ & $\begin{array}{c}\text { 500mg } 1 \text { hora antes } \\
\text { do procedimento }\end{array}$ & $\begin{array}{l}15 \mathrm{mg} / \mathrm{kg} 1 \text { hora } \\
\text { antes do } \\
\text { procedimento. }\end{array}$ & $\begin{array}{l}\text { Profilaxia } \\
\text { antibiótica }\end{array}$ & $\begin{array}{c}\text { Pacientes com } \\
\text { hipersensibilidade à } \\
\text { azitromicina, } \\
\text { eritromicina, a qualquer } \\
\text { antibiótico macrolídeo e } \\
\text { cetolídeo }\end{array}$ & $\begin{array}{c}\text { Baixos relatos de } \\
\text { reações indesejadas. }\end{array}$ \\
\hline $\begin{array}{l}\text { CLARITROMICIN } \\
\text { A ORAL VIA }\end{array}$ & $\begin{array}{l}500 \mathrm{mg} 1 \text { hora antes } \\
\text { do procedimento. }\end{array}$ & $\begin{array}{l}15 \mathrm{mg} / \mathrm{kg} 1 \text { hora } \\
\text { antes do } \\
\text { procedimento. }\end{array}$ & $\begin{array}{l}\text { Profilaxia } \\
\text { antibiótica }\end{array}$ & $\begin{array}{c}\text { Pacientes com } \\
\text { hipersensibilida aos } \\
\text { antibióticos } \\
\text { macrolídeos, histórioco } \\
\text { de arritimia ventricular } \\
\text { cardíaca, insuficiência } \\
\text { hepática grave. }\end{array}$ & $\begin{array}{l}\text { Insônia, cefaleia, } \\
\text { diarreia, vômitos, } \\
\text { náusea, dor } \\
\text { abdominal. }\end{array}$ \\
\hline
\end{tabular}




\subsection{Analgésicos}

Dor é uma experiência sensorial e emocional desagradável, associada a um dano tecidual real ou potencial, sendo a dor dentária e orofacial a mais comum. No tratamento da dor leve a moderada, utilizamos os analgésicos não opioides (dipirona, paracetamol e ibuprofeno), onde estes atuam de forma periférica na intercepção da dor e ação antipirética (Santini, 2015). Já para dores de grau intenso, abrimos mão dos analgésicos opioides (tramadol, paracetamol + codeína), os quais atuam no sistema nervoso central (Graujac, 2006). A seguir na Tabela 3, estão listados os analgésicos mais comumente usados em âmbito clínico.

Tabela 3: analgésicos mais comumente utilizados em âmbito clínico.

\begin{tabular}{|c|c|c|c|c|c|}
\hline DROGA & $\begin{array}{l}\text { POSOLOGIA } \\
\text { ADULTA }\end{array}$ & $\begin{array}{l}\text { POSOLOGIA } \\
\text { PEDIÁTRICA }\end{array}$ & INDICAÇÃO & $\begin{array}{l}\text { CONTRA } \\
\text { INDICAÇÕES }\end{array}$ & $\begin{array}{l}\text { REAÇÕES } \\
\text { ADVERSAS }\end{array}$ \\
\hline $\begin{array}{l}\text { DIPIRONA } \\
\text { SÓDICA 500MG } \\
\text { SOLUČ̃̃O ORAL } \\
\text { GOTAS }\end{array}$ & 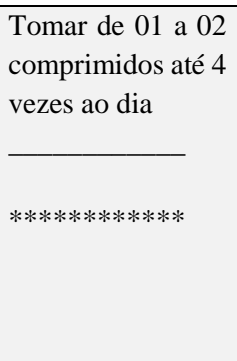 & $\begin{array}{l} \\
\text { Tomar } 01 \text { gota para } \\
\text { cada } 02 \mathrm{~kg} \text { a cada } 04 \\
\text { horas, no máximo } 20 \\
\text { gotas. }\end{array}$ & $\begin{array}{lr}\text { Analgésico para } \\
\text { dores leves } & \text { a } \\
\text { moderada } & \text { e } \\
\text { antitérmico. } & \end{array}$ & $\begin{array}{l}\text { Pacientes com } \\
\text { hipersensibilidade a } \\
\text { dipirona, função de } \\
\text { medula óssea prejudicada, } \\
\text { pacientes com história de } \\
\text { reações anaflactoides e } \\
\text { mulheres nos } 3 \text { primeiros } \\
\text { e } 3 \text { últimos meses de } \\
\text { gestação. }\end{array}$ & $\begin{array}{l}\text { Reações raras como: } \\
\text { granulocitopineia } \\
\text { agranulocitose, reações } \\
\text { alérgicas cutânea e em } \\
\text { mucosas, principalmente } \\
\text { boca e garganta. }\end{array}$ \\
\hline $\begin{array}{l}\text { PARACETAMOL } \\
\text { SUSPENSÃO } \\
\text { ORAL 32MG/ML }\end{array}$ & $\begin{array}{l}\text { Tomar } 01 \\
\text { comprimido de } 03 \\
\text { a } 05 \text { vezes ao dia, } \\
\text { não ultrapassando } \\
\text { 3,5g diários. } \\
\\
* * * * * * * * * * *\end{array}$ & \begin{tabular}{lr}
$* * * * * * * * * * * *$ & \\
& \\
\cline { 1 - 1 } & \\
Tomar & $10-15$ \\
$\mathrm{mg} / \mathrm{kg} / \mathrm{dose}$, & $\mathrm{com}$ \\
intervalos de & $06-06$ \\
horas, 01 gota/kg, não \\
ultrapassando \\
gotas.
\end{tabular} & $\begin{array}{l}\text { Redução da febre } \\
\text { e o alívio } \\
\text { temporário de } \\
\text { dores leves a } \\
\text { moderadas }\end{array}$ & $\begin{array}{lr}\text { Pacientes } & \text { com } \\
\text { hipersensibilidade } & \text { ao } \\
\text { paracetamol, paciente } \\
\text { usuários de varfarina } \\
\text { sódica, }\end{array}$ & $\begin{array}{l}\text { Baixos relatos de reações } \\
\text { indesejadas. }\end{array}$ \\
\hline $\begin{array}{l}\text { IBUPROFENO } \\
\text { 200MG }\end{array}$ & $\begin{array}{l}\text { Tomar } 01 \text { ou } 02 \\
\text { comprimidos de } \\
200 \mathrm{mg} \text { com } \\
\text { intervalos } \\
\text { mínimos de } 04 \\
\text { horas, não } \\
\text { ultrapassando } \\
\text { 1200mg diários. }\end{array}$ & & $\begin{array}{l}\text { Indicado no } \\
\text { alívio temporário } \\
\text { da febre e de } \\
\text { dores de leve a } \\
\text { moderada } \\
\text { intensidade }\end{array}$ & $\begin{array}{l}\text { Pacientes que apresentam } \\
\text { hipersensibilidade ao } \\
\text { ibuprofeno, a } \\
\text { antinflamatório-não- } \\
\text { esteroide, faixa etária de } \\
\text { menores de } 12 \text { anos de } \\
\text { idade, alergia ao ácido } \\
\text { acetilsalicílico e gestantes } \\
\text { nos últimos } 3 \text { meses de } \\
\text { gravides. }\end{array}$ & $\begin{array}{lr}\text { Dor abdominal } & \text { com } \\
\text { cólicas, tontura, azia, } \\
\text { náuseas, } \\
\text { cutâneo. }\end{array}$ \\
\hline $\begin{array}{l}\text { TRAMADOL } \\
\text { 50MG }\end{array}$ & $\begin{array}{l}\text { Tomar } 01 \\
\text { comprimido de } 50 \\
-100 \mathrm{mg} \text { a cada } 04 \\
\text { ou } 06 \text { horas. Sem } \\
\text { ultrapassar } 400 \mathrm{mg} \\
\text { diários. }\end{array}$ & & $\begin{array}{lr}\text { Tratamento da } \\
\text { dor } \\
\text { intensidade } \\
\text { moderada } \\
\text { grave; abecessos } \\
\text { dentoalveolar }\end{array}$ & $\begin{array}{l}\text { Contraindicado } \\
\text { pacientes que apresentam } \\
\text { hipersensibilidade a } \\
\text { tramadol; intoxicações } \\
\text { agudas por álcool, } \\
\text { hipnóticos, analgésicos, } \\
\text { opioides e outros } \\
\text { psicotrópicos; mulheres } \\
\text { grávidas; pacientes } \\
\text { menores de } 16 \text { anos. }\end{array}$ & $\begin{array}{l}\text { Tontura, dor de cabeça, } \\
\text { sonolência, naúsea, boca } \\
\text { seca, constipação, } \\
\text { hiperidorse e fadiga, } \\
\text { alteração de humor. }\end{array}$ \\
\hline $\begin{array}{l}\text { PARACETAMOL } \\
+ \text { FOSFATO DE } \\
\text { CODEÍNA 500MG } \\
+ \text { 30MG }\end{array}$ & $\begin{array}{l}\text { Tomar } \quad 01 \\
\text { comprimido a } \\
\text { cada } 06 \text { horas. } \\
\text { Não ultrapassando } \\
08 \text { comprimidos } \\
\text { diários. }\end{array}$ & & $\begin{array}{l}\text { Indicado para o } \\
\text { alívio de dores de } \\
\text { grau moderado a } \\
\text { intenso; pós- } \\
\text { exodontias; } \\
\text { neuralgias. }\end{array}$ & $\begin{array}{l}\text { Hipersensibilidade } \\
\text { paracetamol e/ou à } \\
\text { codeína; mães que } \\
\text { amamentem. }\end{array}$ & $\begin{array}{l}\text { Naúsea, vômito, } \\
\text { sonolência, tontura e } \\
\text { hiperidrose, alteração de } \\
\text { humor. }\end{array}$ \\
\hline
\end{tabular}




\subsection{Antivirais}

Dentro das doenças virais infectocontagiosas existentes, a que mais prevalece acometendo a cavidade oral são as causadas pelo vírus herpes humano (HSV) (Consolaro, 2009; Andrade, 2014). O Herpes labial é uma doença causada pelo HSV1 podendo se manifestar em duas formas clínicas, a primária e a manifestação recorrente. A estomatite herpética primária (EHP) caracteriza-se por envolvimento e sistêmico causando febre, dor, ulcerações múltiplas na cavidade oral, dificuldade de deglutir e perda de apetite, tendo como tratamento o controle dos sintomas e redução da duração das lesões (Andrade, 2014) Já o Herpes labial, ou recorrente, causado pelo HSV-2, apresenta-se com sintomas de prurido, ardência, dor no local e múltiplas vesículas, que se rompem liberando secreção (Marotti et al., 2008). Sabe-se que os sinais e sintomas podem perdurar entre 10 e 14 dias, onde os tratamentos visam minimizar o período e extensões da manifestação (Andrade, 2014). A seguir, a Tabela 4 lista os medicamentos mais utilizados no tratamento desta lesão.

Tabela 4: antivirais de primeira escolha no tratamento da EHP.

\begin{tabular}{|c|c|c|c|c|c|}
\hline DROGA & $\begin{array}{l}\text { POSOLOGIA } \\
\text { ADULTA }\end{array}$ & $\begin{array}{l}\text { POSOLOGIA } \\
\text { PEDIÁTRICA }\end{array}$ & INDICAÇÕES & $\begin{array}{l}\text { CONTRA- } \\
\text { INDICAÇÕES }\end{array}$ & $\begin{array}{l}\text { REAÇÕES } \\
\text { ADVERSAS }\end{array}$ \\
\hline $\begin{array}{l}\text { ACICLOVIR } \\
\underline{200 \mathrm{MG}}\end{array}$ & $\begin{array}{l}\text { Tomar } 01 \\
\text { comprimido a cada } \\
05 \text { horas durante } 05- \\
07 \text { dias }\end{array}$ & $\begin{array}{l}\text { Tomar metade da } \\
\text { dose de 200mg } \\
(100 \mathrm{mg}), 04 \text { vezes } \\
\text { ao dia durante } 05 \\
\text { dias. }\end{array}$ & $\begin{array}{l}\text { Tratamento de } \\
\text { infecções cutâneas } \\
\text { pelo vírus Herpes } \\
\text { simplex, incluindo } \\
\text { herpes genital e } \\
\text { labial, inicial e } \\
\text { recorrente. }\end{array}$ & $\begin{array}{ll}\text { Pacientes } & \text { com } \\
\text { conhecida } & \\
\text { hipersensibilidade } & \text { ao } \\
\text { aciclovir ou } & \text { ao } \\
\text { valaciclovir. } & \end{array}$ & $\begin{array}{l}\text { Dor de cabeça, } \\
\text { tontura, vômito, } \\
\text { fotossensibilidade }\end{array}$ \\
\hline $\begin{array}{l}\text { ACICLOVIR } \\
\underline{\text { 50MG/G CREME }} \\
\underline{\text { DERMATOLÓGI }} \\
\underline{\text { CO }}\end{array}$ & $\begin{array}{l}\text { Aplicar o creme } 05 \\
\text { vezes ao dia no } \\
\text { local, a cada } 04 \\
\text { horas, suspendo a } \\
\text { aplicação no período } \\
\text { noturno }\end{array}$ & $\begin{array}{lr}\text { Aplicar o creme } & 05 \\
\text { vezes ao dia } & \text { no } \\
\text { local, a cada } & 04 \\
\text { horas, suspendo a } \\
\text { aplicação no período } \\
\text { noturno }\end{array}$ & $\begin{array}{l}\text { Tratamento de } \\
\text { infecções cutâneas } \\
\text { pelo vírus Herpes } \\
\text { simplex, incluindo } \\
\text { herpes genital e } \\
\text { labial, inicial e } \\
\text { recorrente. }\end{array}$ & $\begin{array}{ll}\text { Pacientes } & \text { com } \\
\text { hipersensibilidade } & \\
\text { conhecida } & \text { ao } \\
\text { aciclovir, } & \text { ao } \\
\text { valaciclovir, } & \text { ao } \\
\text { propilenoglicol. } & \end{array}$ & \begin{tabular}{lrr} 
Não & apresenta \\
reações & \multicolumn{2}{r}{ adversas } \\
comuns & ou & muito \\
comuns. & &
\end{tabular} \\
\hline
\end{tabular}

Fonte: Autores.

\subsection{Anti-Inflamatórios Esteroidais}

Os anti-inflamatórios esteroidais (AIES), também denominados corticoides, são drogas que mimetizam o cortisol, hormônio produzido na glândula adrenal, diretamente relacionado com o sistema imunológico e combate a inflamação (Simone et al. 2013). Estes fármacos atuam inibindo a enzima fosfolipase A2, diminuindo assim a disponibilidade de ácido araquidônico na célula, provocando a diminuição de metabólitos da ciclooxigenase 1 e 2(COX1 e COX2).

Através desse mecanismo, os glicocorticóides diminuem as manifestações clínicas sintomáticas (Carriches et al. 2006.; Souza et al. 2015). Na odontologia, esta droga é na maioria das vezes administrada de forma preemptiva (antes da consulta), de modo a diminuir os sinais cardeais da inflamação (dor, calor, rubor, edema e perda de função (Simone et al., 2015; Melo, 2013). A seguir, na Tabela 5 estão listados os AIES mais utilizados no cotidiano clínico. 
Tabela 5: AIES mais comumente utilizados em âmbito clínico.

\begin{tabular}{|c|c|c|c|c|c|}
\hline DROGA & $\begin{array}{c}\text { POSOLOGIA } \\
\text { ADULTA }\end{array}$ & $\begin{array}{l}\text { POSOLOGIA } \\
\text { PEDIÁTRICA } \\
\end{array}$ & INDICAÇÕES & $\begin{array}{c}\text { CONTRA- } \\
\text { INDICAÇÕES } \\
\end{array}$ & $\begin{array}{c}\text { EFEITOS } \\
\text { ADVERSOS } \\
\end{array}$ \\
\hline$\frac{\text { DEXAMETASONA }}{\underline{0,5 M G}}$ & $\begin{array}{l}\text { Tomar } 1 \\
\text { comprimido, } 1 \\
\text { hora antes da } \\
\text { cirurgia. }\end{array}$ & $\begin{array}{l}\text { Tomar } 1 \\
\text { comprimido, } 1 \\
\text { hora antes do } \\
\text { procedimento }\end{array}$ & $\begin{array}{l}\text { Tratamento de } \\
\text { doenças agudas e } \\
\text { crônicas que } \\
\text { respondem aos } \\
\text { corticoides, } \\
\text { tratamento } \\
\text { preemptivo em } \\
\text { cirurgias orais. }\end{array}$ & $\begin{array}{l}\text { Infecções fúngicas } \\
\text { sistêmicas, } \\
\text { hipersensibilidade à } \\
\text { sulfitos, } \\
\text { administração de } \\
\text { vacinas de vírus } \\
\text { vivo, lactentes. }\end{array}$ & $\begin{array}{l}\text { O uso prolongado } \\
\text { pode causar catarata, } \\
\text { glaucoma, retenção } \\
\text { hidrossalina, aumento } \\
\text { da pressão arterial e } \\
\text { insuficiência } \\
\text { adrenocortical }\end{array}$ \\
\hline $\begin{array}{c}\text { DEXAMETASONA } \\
2 M G\end{array}$ & $\begin{array}{l}\text { Tomar } 1 \\
\text { comprimido, } 1 \\
\text { hora antes da } \\
\text { cirurgia. }\end{array}$ & $\begin{array}{l}\text { Tomar } 1 \\
\text { comprimido, } 1 \\
\text { hora antes do } \\
\text { procedimento }\end{array}$ & $\begin{array}{l}\text { Tratamento de } \\
\text { doenças agudas e } \\
\text { crônicas que } \\
\text { respondem aos } \\
\text { corticoides, } \\
\text { tratamento } \\
\text { preemptivo em } \\
\text { cirurgias orais. }\end{array}$ & $\begin{array}{l}\text { Infecções fúngicas } \\
\text { sistêmicas, } \\
\text { hipersensibilidade à } \\
\text { sulfitos, } \\
\text { administração de } \\
\text { vacinas de vírus } \\
\text { vivo, lactentes. }\end{array}$ & $\begin{array}{l}\text { O uso prolongado } \\
\text { pode causar catarata, } \\
\text { glaucoma, retenção } \\
\text { hidrossalina, aumento } \\
\text { da pressão arterial e } \\
\text { insuficiência } \\
\text { adrenocortical }\end{array}$ \\
\hline$\frac{\text { DEXAMETASONA }}{\underline{4 M G}}$ & $\begin{array}{l}\text { Tomar } 1 \\
\text { comprimido, } 1 \\
\text { hora antes da } \\
\text { cirurgia }\end{array}$ & $\begin{array}{l}\text { Tomar } 1 \\
\text { comprimido, } 1 \\
\text { hora antes do } \\
\text { procedimento }\end{array}$ & $\begin{array}{l}\text { Tratamento de } \\
\text { doenças agudas e } \\
\text { crônicas que } \\
\text { respondem aos } \\
\text { corticoides, } \\
\text { tratamento } \\
\text { preemptivo em } \\
\text { cirurgias orais. }\end{array}$ & $\begin{array}{l}\text { Infecções fúngicas } \\
\text { sistêmicas, } \\
\text { hipersensibilidade à } \\
\text { sulfitos, } \\
\text { administração de } \\
\text { vacinas de vírus } \\
\text { vivo, lactentes. }\end{array}$ & $\begin{array}{l}\text { O uso prolongado } \\
\text { pode causar catarata, } \\
\text { glaucoma, retenção } \\
\text { hidrossalina, aumento } \\
\text { da pressão arterial e } \\
\text { insuficiência } \\
\text { adrenocortical }\end{array}$ \\
\hline$\frac{\text { BETAMETASONA }}{\underline{0,5 M G}}$ & $\begin{array}{l}\text { Tomar } 1 \\
\text { comprimido, } 1 \\
\text { hora antes da } \\
\text { cirurgia. }\end{array}$ & $\begin{array}{l}\text { Ingerir } 26 \\
\text { gotas }(0,5 \mathrm{mg}) 1 \\
\text { hora antes do } \\
\text { procedimento. }\end{array}$ & $\begin{array}{l}\text { Tratamento de } \\
\text { doenças agudas e } \\
\text { crônicas que } \\
\text { respondem aos } \\
\text { corticoides, } \\
\text { tratamento } \\
\text { preemptivo em } \\
\text { cirurgias orais. }\end{array}$ & $\begin{array}{l}\text { Infecções fúngicas } \\
\text { sistêmicas, } \\
\text { hipersensibilidade à } \\
\text { sulfitos, } \\
\text { administração de } \\
\text { vacinas de vírus } \\
\text { vivo, lactentes. }\end{array}$ & $\begin{array}{l}\text { O uso prolongado } \\
\text { pode causar catarata, } \\
\text { glaucoma, retenção } \\
\text { hidrossalina, aumento } \\
\text { da pressão arterial e } \\
\text { insuficiência } \\
\text { adrenocortical }\end{array}$ \\
\hline$\frac{\text { BETAMETASONA }}{\underline{\text { MG }}}$ & $\begin{array}{l}\text { Tomar } 1 \\
\text { comprimido, } 1 \\
\text { hora antes da } \\
\text { cirurgia. }\end{array}$ & $* * * * * * * * * * * *$ & $\begin{array}{l}\text { Tratamento de } \\
\text { doenças agudas e } \\
\text { crônicas que } \\
\text { respondem aos } \\
\text { corticoides, } \\
\text { tratamento } \\
\text { preemptivo em } \\
\text { cirurgias orais. }\end{array}$ & $\begin{array}{l}\text { Infecções fúngicas } \\
\text { sistêmicas, } \\
\text { hipersensibilidade à } \\
\text { sulfitos, } \\
\text { administração de } \\
\text { vacinas de vírus } \\
\text { vivo, lactentes. }\end{array}$ & $\begin{array}{l}\text { O uso prolongado } \\
\text { pode causar catarata, } \\
\text { glaucoma, retenção } \\
\text { hidrossalina, aumento } \\
\text { da pressão arterial e } \\
\text { insuficiência } \\
\text { adrenocortical }\end{array}$ \\
\hline $\begin{array}{l}\text { TRIANCINOLONA } \\
\text { ORABASE 1MG/G }\end{array}$ & $\begin{array}{l}\text { Aplicar na área } \\
\text { indicada, duas } \\
\text { vezes ao dia, } \\
\text { durante três } \\
\text { dias. }\end{array}$ & $\begin{array}{l}\text { Aplicar na área } \\
\text { indicada, duas } \\
\text { vezes ao dia, } \\
\text { durante três dias. }\end{array}$ & $\begin{array}{l}\text { Ulcerações intra- } \\
\text { orais causadas } \\
\text { por trauma, ou } \\
\text { ulcerações aftosa } \\
\text { recorrentes }\end{array}$ & $\begin{array}{l}\text { Infecções fúngicas, } \\
\text { virais ou } \\
\text { bacterianas na boca } \\
\text { ou garganta. }\end{array}$ & $\begin{array}{l}\text { Sensibilização ou } \\
\text { irritação local. }\end{array}$ \\
\hline
\end{tabular}

Fonte: Autores.

\subsection{Anti-Inflamatórios Não Esteroidais}

Assim como os corticoides, os anti-inflamatórios não esteroidais (AINEs) também atuam sob o controle da dor e inflamação. Diferentemente dos glicocorticóides, os AINEs atuam diretamente nas ciclooxigenases 1 e/ou 2, a depender se ele for seletivo a COX2, ou não seletivo (Souza et al., 2015; Melo, 2013). Na Tabela 6 a seguir, poderão ser observados os fármacos mais utilizados que seguem este princípio terapêutico. 
Tabela 6: AINEs mais comumente utilizados em âmbito clínico.

\begin{tabular}{|c|c|c|c|c|c|}
\hline DROGA & $\begin{array}{l}\text { POSOLOGIA } \\
\text { ADULTA }\end{array}$ & $\begin{array}{l}\text { POSOLOGIA } \\
\text { PEDIÁTRICA }\end{array}$ & INDICAÇÕES & $\begin{array}{l}\text { CONTRA- } \\
\text { INDICAÇÕES }\end{array}$ & $\begin{array}{l}\text { EFEITOS } \\
\text { ADVERSOS }\end{array}$ \\
\hline $\begin{array}{l}\text { CETOPROFENO } \\
20 \mathrm{MG}\end{array}$ & 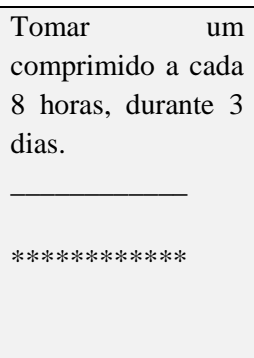 & $\begin{array}{l}\text { Acima de } 1 \text { ano: } 1 \\
\text { gota por kg de peso, } \\
\text { a cada } 6 \text { ou } 8 \text { horas; } \\
7 \text { a } 11 \text { anos: } 25 \\
\text { gotas, a cada } 6 \text { ou } 8 \\
\text { horas.OBS. } \\
\text { POSOLOGIA } \\
\text { PARA A VERSÃO } \\
\text { DE 20mg. }\end{array}$ & $\begin{array}{l}\text { Contusões, } \\
\text { fraturas, luxações e } \\
\text { pós-operatório. }\end{array}$ & $\begin{array}{l}\text { Ulcera } \\
\text { peptica/hemorrágica; } \\
\text { insuficiência cardíaca, } \\
\text { renal ou hepática } \\
\text { severa; perfuração ou } \\
\text { sangramento gástrico; } \\
\text { gestantes do } 3^{\circ} \\
\text { trimestre. }\end{array}$ & $\begin{array}{l}\text { Anemia hemorrágica, } \\
\text { parestesia, asma, } \\
\text { dispepsia, náusea, dor } \\
\text { abdominal, vômito. }\end{array}$ \\
\hline $\begin{array}{l}\text { DICLOFENACO } \\
\text { POTÁSSICO 50MG }\end{array}$ & $\begin{array}{l}\text { Tomar } 1 \\
\text { comprimido a cada } \\
8 \text { horas, durante } 3 \\
\text { dias. }\end{array}$ & $\begin{array}{l}\text { Não recomendado } \\
\text { para crianças e } \\
\text { adolescentes } \\
\text { abaixo de } 14 \text { anos. }\end{array}$ & $\begin{array}{lr}\text { Estados de } & \text { dor e } \\
\text { inflamação } & \text { pós- } \\
\text { operatórios, } & \text { pós- } \\
\text { traumáticos } & \text { e em } \\
\text { quadros } & \text { de } \\
\text { inflamação } & \text { grave } \\
\text { de garganta. } & \end{array}$ & $\begin{array}{l}\text { Ulcera } \\
\text { peptica/hemorrágica; } \\
\text { insuficiência cardíaca, } \\
\text { renal ou hepática } \\
\text { severa; perfuração ou } \\
\text { sangramento gástrico; } \\
\text { gestantes do } 3^{\circ} \\
\text { trimestre. }\end{array}$ & $\begin{array}{lr}\text { Cefaléia, } & \text { tontura, } \\
\text { epigastralgia, } & \text { náusea, } \\
\text { vômito, } & \text { diarreia, } \\
\text { dispepsia, } & \text { cólicas } \\
\text { abdominais } & \end{array}$ \\
\hline $\begin{array}{l}\text { DICLOFENACO } \\
\text { SÓDICO 50MG }\end{array}$ & $\begin{array}{l}\text { Tomar } 1 \\
\text { comprimido a cada } \\
8 \text { horas, durante } 3 \\
\text { dias }\end{array}$ & $\begin{array}{l}\text { Não recomendado } \\
\text { para crianças e } \\
\text { adolescentes } \\
\text { abaixo de } 14 \text { anos. }\end{array}$ & $\begin{array}{lr}\text { Estados de } & \text { dor e } \\
\text { inflamação } & \text { pós- } \\
\text { operatórios, } & \text { pós- } \\
\text { traumáticos } & \text { e } \\
\text { em } \\
\text { quadros } & \text { de } \\
\text { inflamação } & \text { grave } \\
\text { de garganta. } & \end{array}$ & $\begin{array}{l}\text { Ulcera } \\
\text { peptica/hemorrágica; } \\
\text { insuficiência cardíaca, } \\
\text { renal ou hepática } \\
\text { severa; perfuração ou } \\
\text { sangramento gástrico; } \\
\text { gestantes do } 3^{\circ} \\
\text { trimestre. }\end{array}$ & $\begin{array}{lr}\text { Cefaléia, } & \text { tontura, } \\
\text { epigastralgia, } & \text { náusea, } \\
\text { vômito, } & \text { diarreia, } \\
\text { dispepsia, } & \text { cólicas } \\
\text { abdominais } & \end{array}$ \\
\hline $\begin{array}{l}\text { IBUPROFENO } \\
\underline{\text { 400MG }}\end{array}$ & 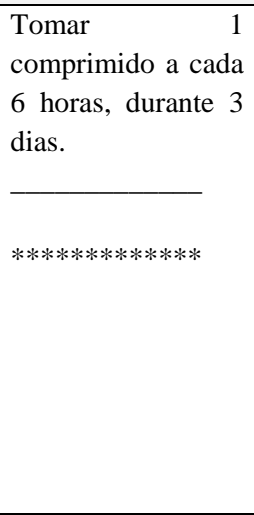 & 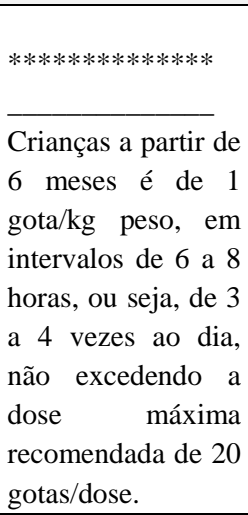 & $\begin{array}{l}\text { Condições que } \\
\text { requeiram } \\
\text { atividade anti- } \\
\text { inflamatória e/ou } \\
\text { analgésica, } \\
\text { distúrbios } \\
\text { musculoesquelético } \\
\text { s, pós-operatório e } \\
\text { pôs-traumatismo. }\end{array}$ & $\begin{array}{l}\text { Ulcera } \\
\text { peptica/hemorrágica; } \\
\text { insuficiência cardíaca, } \\
\text { renal ou hepática } \\
\text { severa; perfuração ou } \\
\text { sangramento gástrico; } \\
\text { asma bronquica; } \\
\text { gestantes do } 3^{\circ} \\
\text { trimestre. }\end{array}$ & $\begin{array}{l}\text { Sintomas } \\
\text { gastrintestinais são os } \\
\text { mais frequentemente } \\
\text { encontrados }\end{array}$ \\
\hline $\begin{array}{l}\text { NIMESULIDA } \\
\underline{100 \mathrm{MG}}\end{array}$ & $\begin{array}{l}\text { Tomar } 1 \\
\text { comprimido a cada } \\
12 \text { horas, durante } 3 \\
\text { dias. }\end{array}$ & $\begin{array}{l}\text { Administrar } 1 \text { gota } \\
\text { por kg de peso, } \\
\text { duas vezes ao dia, } \\
\text { diretamente na } \\
\text { boca da criança ou } \\
\text { se preferir diluída } \\
\text { em um pouco de } \\
\text { água açucarada. }\end{array}$ & $\begin{array}{l}\text { Estados de } \\
\text { inflamação e } \\
\text { operatórios, pós- } \\
\text { traumáticos ou em } \\
\text { qualquer } \\
\text { quadro outro } \\
\text { necessite de ação } \\
\text { antiinflamatória, } \\
\text { analgésica } \\
\text { antipirética. }\end{array}$ & $\begin{array}{l}\text { Ulcera } \\
\text { peptica/hemorrágica; } \\
\text { insuficiência cardíaca, } \\
\text { renal ou hepática } \\
\text { severa; perfuração ou } \\
\text { sangramento gástrico. }\end{array}$ & $\begin{array}{l}\text { Diarreia, náusea } \mathrm{e} \\
\text { vômito. }\end{array}$ \\
\hline PIROXICAM 20MG & $\begin{array}{l}\text { Tomar } 1 \text { capsula } \\
\text { por dia, durante } 3 \\
\text { dias. }\end{array}$ & $\begin{array}{l}\text { Não recomendo } \\
\text { para crianças e } \\
\text { adolescentes } \\
\text { abaixo de } 12 \text { anos. }\end{array}$ & $\begin{array}{l}\text { Condições que } \\
\text { requeiram } \\
\text { atividade anti- } \\
\text { inflamatória e/ou } \\
\text { analgésica, } \\
\text { distúrbios } \\
\text { musculoesquelético } \\
\text { s, pós-operatório e } \\
\text { pôs-traumatismo. }\end{array}$ & $\begin{array}{l}\text { Ulcera } \\
\text { peptica/hemorrágica; } \\
\text { insuficiência cardíaca, } \\
\text { renal ou hepática } \\
\text { severa; perfuração ou } \\
\text { sangramento gástrico. }\end{array}$ & $\begin{array}{l}\text { Sintomas } \\
\text { gastrintestinais são os } \\
\text { mais frequentemente } \\
\text { encontrados }\end{array}$ \\
\hline
\end{tabular}




\subsection{Antifúngicos}

No âmbito odontológico pode-se também encontrar lesões causadas por fungos. A mais comum delas é a candidíase oral, que se caracteriza como uma infecção produzida pelos microorganismos Candida sp, sendo a espécie albicans, a que mais acomete o meio bucal. Trata-se de uma infecção oportunista, visto que este fungo é um habitante natural do sítio anatômico oral, porém torna-se patológico principalmente em indivíduos imunossuprimidos (Mangueira et al., 2010; Siqueir et al., 2014). A candidíase pode se apresentar nas formas clínicas pseudomembranosa, eritematosa, crônica hiperplásica e queilite angular, podendo ocorrer mais. De um tipo no mesmo indivíduo ao mesmo tempo (Mangueira et al. 2010; Vieira et al. 2012). Tendo em vista o número de casos, e a importância do tratamento, está esquematizada na Tabela 7, a terapêutica para o tratamento dessas afecções.

Tabela 7: Antifúngicos de prescrição mais comum no âmbito clínico.

\begin{tabular}{|c|c|c|c|c|c|}
\hline DROGA & $\begin{array}{l}\text { POSOLOGIA } \\
\text { ADULTA }\end{array}$ & $\begin{array}{l}\text { POSOLOGIA } \\
\text { PEDIÁTRICA }\end{array}$ & INDICAÇÕES & $\begin{array}{l}\text { CONTRA- } \\
\text { INDICAÇÕES }\end{array}$ & $\begin{array}{l}\text { EFEITOS } \\
\text { ADVERSOS }\end{array}$ \\
\hline $\begin{array}{l}\text { FLUCONAZOL } \\
\underline{100 M G}\end{array}$ & $\begin{array}{l}\text { Tomar } 1 \\
\text { comprimido a cada } \\
12 \text { horas, durante } 7 \\
\text { dias. }\end{array}$ & $\begin{array}{l}\text { Não recomendado } \\
\text { para menores de } \\
18 \text { anos. }\end{array}$ & $\begin{array}{l}\text { Candidíase nas } \\
\text { suas mais variadas } \\
\text { formas. }\end{array}$ & $\begin{array}{l}\text { Gestantes, } \\
\text { coadministração de } \\
\text { terfenadina, cisaprida, } \\
\text { astemizol, } \\
\text { eritromicina, } \\
\text { pimozida e quinidina. }\end{array}$ & $\begin{array}{l}\text { Cefaleia, rash cutâneo, } \\
\text { dor abdominal, } \\
\text { diarreia, náuseas e } \\
\text { vômito. }\end{array}$ \\
\hline $\begin{array}{l}\text { FLUCONAZOL } \\
\underline{\text { 150MG }}\end{array}$ & $\begin{array}{lr}\text { Tomar } & 1 \\
\text { comprimido por } \\
\text { semana, durante } 4 \\
\text { semanas. }\end{array}$ & $\begin{array}{l}\text { Não recomendado } \\
\text { para menores de } \\
18 \text { anos. }\end{array}$ & $\begin{array}{l}\text { Candidíase nas } \\
\text { suas mais variadas } \\
\text { formas. }\end{array}$ & $\begin{array}{l}\text { Gestantes, } \\
\text { coadministração de } \\
\text { terfenadina, cisaprida, } \\
\text { astemizol, } \\
\text { eritromicina, } \\
\text { pimozida e quinidina. }\end{array}$ & $\begin{array}{l}\text { Cefaleia, rash cutâneo, } \\
\text { dor abdominal, } \\
\text { diarreia, náuseas e } \\
\text { vômito. }\end{array}$ \\
\hline $\begin{array}{l}\text { NISTATINA } \\
\text { SUSPENSÃO } \\
\text { ORAL 100.000 UI } \\
\end{array}$ & $\begin{array}{l}\text { Bochechar } 6 \mathrm{ml} \text { da } \\
\text { solução a cada } 6 \\
\text { horas, durante } 15 \\
\text { dias. }\end{array}$ & $\begin{array}{l}\text { Prematuros: } \\
\text { Limpeza com } 1 \\
\mathrm{~mL} \text { a cada } 6 \text { horas } \\
\text { durante } 15 \text { dias. } \\
\text { Lactentes: limpeza } \\
\text { com } 2 \mathrm{~mL} \text { a cada } 6 \\
\text { horas, durante } 15 \\
\text { dias. }\end{array}$ & $\begin{array}{l}\text { Tratamento da } \\
\text { candidíase oral e } \\
\text { do trato } \\
\text { gastrointestinal } \\
\text { superior. }\end{array}$ & $\begin{array}{l}\text { Hipersensibilidade a } \\
\text { algum dos } \\
\text { componentes. }\end{array}$ & $\begin{array}{l}\text { Diarreia, distúrbios } \\
\text { gastrintestinais, } \\
\text { náuseas e vômitos. }\end{array}$ \\
\hline $\begin{array}{l}\text { CETOCONAZOL } \\
\text { CREME }\end{array}$ & $\begin{array}{l}\text { Aplicar na área } \\
\text { infectada } 1 \text { vez ao } \\
\text { dia, durante } 4 \\
\text { semanas. }\end{array}$ & $\begin{array}{l}\text { Aplicar na área } \\
\text { infectada } 1 \text { vez ao } \\
\text { dia, durante } 4 \\
\text { semanas. }\end{array}$ & & 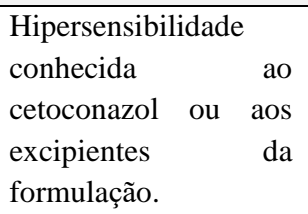 & $\begin{array}{l}\text { Eritema, prurido e } \\
\text { sensação de ardência } \\
\text { no local de aplicação }\end{array}$ \\
\hline
\end{tabular}

Fonte: Autores.

\section{Conclusão}

A farmacologia é uma ciência vasta e complexa, não admitindo erros graves, pois estes levam o aluno e/ou o CD a um fracasso no tratamento com os fármacos. Auxiliar na prescrição de medicamentos, disponibilizando o acesso gratuito à informação através de um aparelho móvel, traz ao acadêmico de odontologia e/ou profissional formado, um respaldo no porquê da utilização da droga, suas complicações, dosagens, etc., dando-lhe maior conforto e segurança ao indicar uma terapia farmacológica.

Concluindo então, a ideia central do presente trabalho, a elaboração de um protocolo farmacoterápico com enfoque odontológico, alicerçado sob embasamento científico de literaturas recentes e acessível a todos. 


\section{Referências}

American dental association ADA (2016) Oral health topics. < http://www.ada.org/en/member-center/oral-health-topics/antibiotic-prophylaxis>.

Andrade, E. D. (2014) Terapêutica medicamentosa em odontologia. (3a ed.), Artes Médicas, 238.

Araújo, L. G., Biagini, F. C., Fernandes, F. L., Caputo, I. G. C, \& Silva, R. H. A. (2012) Conhecimento de acadêmicos de odontologia, sobre os aspectos clínicos, éticos e legais da prescrição medicamentosa. RFO Passo Fundo, 17, 50-54.

Caliari, B. M., Rosa, F. S., Souza, A. C. de, Martins, V. da M., Caliari, L. R., Caliari, L. R., \& Souza, G. R. (2021). Erros nas prescrições medicamentosas odontológicas: um estudo transversal em drogarias. Research, Society and Development, 10(15), e485101522494.

Carriches, C. L., Gozález, J. M. M., \& Rodriguez, M. D. (2006) The use of methylprednisolone versus diclofenac in the treatment of inflamation and trismus after surgical removal of lower third molars. Med Oral Patol Oral Cir Bucal 11: E440-5.

Carvalho, V. A. P., Borgatto, A. F., \& Lopes, L. C. (2010) Nível de conhecimento dos cirurgiões-dentistas de São José dos Campos sobre o uso de antiinflamatórios não esteroides. Ciência \& Saúde Coletiva, 15(1):1773-1782

Consolaro, A., \& Consolaro, A. C. (2009) Herpes simples recorrente naa prática ortodôntica: devemos suspender o atendimento? Maringá, 14, (2):16-24.

Garbin, A. J. I., Garbin, C. S., Saliba, T. A., \& Moroso, T. T. (2006) Implicações legais da prescrição medicamentosa na odontologia. R bras ci Saúde 10(2):151158.

Graujac, C. (2006) Controle da dor e inflamação em cirurgia odontológica. Dissertação (mestrado em odontologia). Faculdade de odontologia do campus de Araçatuba - UNESP - Araçatuba.

Mangueira, D. F. B., Mangueira, L. F. B., \& Diniz, M. F. F. M. (2010) Candidose oral. R Bras Cienc Saúde 14(2):69-72.

Marotti, J.et al. (2008) Tratamento do herpes labial pela terapia fotodinâmica. Rev Assoc Paul Cir Dent 62(5):370-3.

Melo. E. A. C. \& Lobo, P. L. D. (2013) Avaliação do conhecimento de profissionais de saúde sobre o uso de anti-inflamatórios não esteroidais em crianças. Odontol. Clín.-Cient. 12(3) 209-212.

Neves, M., Santoro, M. M. W., Paula, G. S., \& Caetano P. L. (2021). Prescrição medicamentosa em odontologia, suas normas e condutas - uma revisão de literatura. Revista estação cientifica, (25).

Nunes, T. P., Nunes, L. P., Silva, A. N. A., Pirovani, B. O., Morábito, M. J. S. D., de Morais, L. A., Gruba, A. S., \& Nunes, G. P. (2021). Effects adverse of treatment with selective inhibitors of serotonin recaptation on the fetus and neonatalsof mothers with gestational depression: A critical review. Research, Society and Development, 10(4), e11210413937.

Oliveira, I. L. M. (2011) Antimicrobianos de uso odontológico: informação para uma boa prática. Odontol. Clín.-Cient. (3) 217-220.

Pedroso, R. O. (2015) Antibiótico terapia na odontologia. Dissertação (bacharelado em odontologia). Facudade de Pindamonhagaba FAPI, Pindamonhagaba SP.

Santini, M. F. (2015) Comparação entre duas associações de analgésicos não opioides e opioides no controle da dor do abscesso dentoalveolar agudo em evolução: um ensaio clínico randomizado. Dissertação (doutorado em odontologia). Universidade do Rio Grande do Sul - Faculdade de Odontologia - Programa de pós-graduação em odontologia, Porto Alegre.

Santos, R. R. (2015) Endocardite infecciosa: gastos hospitalares e implicações para o tratamento odontológico. Dissertação (bacharelado em odontologia). Universidade de Santa Catarina UFSC.

Silva, R. N. F. \& Pereira, L. C. G. (2016) O uso de anti-inflamatórios esteroidais e não esteroidais no controle da dor e do edema em cirurgia de terceiros molares. Revista Bahiana de Odontologia 7(1).31-39.

Simone, J. L., Jorge, W. A., Horliana, A. C. R. T., Carnaval, T. G., \& Tortamano, I. P. (2013) Comparative analysis of preemptive analgesic effect of dexamethazone and diclofenac following third molar surgery. Braz Oral Res 27(3):266-271.

Siqueira, J. S. S., Batista, S. A., Jr, A. S., Ferreira, M. F., Agostini, M., \& Torres, S. R. (2014) Candidíase oral em pacientes internados em UTI. Rev. Bras. Odontol..71(2):176-179.

Souza, D. S., \& Pereira, S. P. (2021). Terapia Medicamentosa na Odontologia: Revisão de Literatura. Centro Universitário referência em Manhuaçu, Repositório de trabalhos de conclusão de curso. Disponível em: http://www.pensaracademico.facig.edu.br/index.php/repositoriotcc/article/view/3217.

Souza, G. F. M., Silva, K. F. F. B., \& Brito, A. R. M. (2011) Prescrição medicamentosa em odontologia: normas e condutas. Cad. Saúde Colet. 19 (2): $208-214$.

Souza, G. F. M., Caldas, L. C. B., \& Silva, G. S. M. M. (2015) Selective cyclooxigenase-2 inhibitors in dentistry: limitations and adverse effects. Rev Odonto Cienc 30(4):195-199.

Vieira, T. T. P., Sousa, J. P., Soares, M. S. M., Lima, E. O., Paulo, M. Q., \& Carvalho, M. F. F. P. (2012) Candidose bucal em paciente HIV positivo: relato de caso. Odontol. Clín.-Cient. 11 (2): 169-171. 